\title{
PERGAMON
}

www.elsevier.com/locate/watres

\section{THERMAL PYROLYSIS CHARACTERISTICS OF POLYMER FLOCCULATED WASTE ACTIVATED SLUDGE}

\author{
C. P. CHU ${ }^{1}$, D. J. $\mathrm{LEE}^{1 *}$ and C. Y. CHANG \\ ${ }^{1}$ Department of Chemical Engineering, National Taiwan University, Taipei, Taiwan, 10617 and \\ ${ }^{2}$ Graduate Institute of Environmental Engineering, National Taiwan University, Taipei, Taiwan, 10617
}

(First received 29 November 1999; accepted in revised form 22 March 2000)

\begin{abstract}
Polyelectrolyte conditioning is a common practice in wastewater management. This paper experimentally elucidated the thermal pyrolysis characteristics of waste activated sludge at a temperature range of $300-900 \mathrm{~K}\left(27-627^{\circ} \mathrm{C}\right)$ using thermogravimetric analysis (TGA) in inert atmosphere, with especial attention on the effect of polyelectrolyte flocculation (using cationic polyacrylamide). On the pyrolysis rate vs temperature plot two maxima were noted. At the heating rate of $8^{\circ} \mathrm{C} / \mathrm{min}$, polyelectrolyte does not influence the pyrolysis process. As higher heating rates (14 and $20^{\circ} \mathrm{C} / \mathrm{min}$ ), on the other hand, flocculation to charge neutralization point would enhance the rate of thermal pyrolysis. A simple two parallel-reaction kinetic model is applied to interpret the experimental data. Possible roles of flocculant on sludge pyrolysis are discussed on the basis of change in sludge structures and the hindrance of surface reactions of sludge particles. (C) 2000 Elsevier Science Ltd. All rights reserved
\end{abstract}

Key words - pyrolysis, conditioning, sludge, model

\section{INTRODUCTION}

The current methods for disposal of waste activated sludge include landfill with stabilization and incineration. Sludge pyrolysis becomes a potential alternative to treating waste activated sludge from wastewater treatment plant. The pyrolysis process involved the heating of sludge in an inert atmosphere, from which part of the organic matters could be released from the sludge and recycled (Suzuki et al., 1988; Campbell and Bridle, 1989), which matches the appeal of resource utilization. In addition, heavy metals (except mercury and cadmium that are going to their salts) could be safely enclosed in the solid residues (Kaminsky and Kummer, 1989; Kislter et al., 1987). Some researchers employed a fluidized bed to study the pyrolysis of sewage sludge (Kaminsky et al., 1982, 1987; Piskorz et al., 1986, Stammbach et al., 1989).

Thermogravimetric analysis (TGA) is capable of providing pyrolysis kinetic data of sludge at evaluated temperatures (Caballero et al., 1995). A few publications experimentally elucidated the pyrolysis kinetics of sewage sludge with the help of a TGA

\footnotetext{
*Author to whom all correspondence should be addressed. Tel.: +886-2-2362-5230; fax: +886-2-2362-3040; email:djlee@ccms.ntu.edu.tw
}

test (Urban and Antal, 1982; Dumpelmann et al., 1991). However, data interpretation usually faces major difficulties for distinguishing the weight vs temperature data into a complex reaction scheme (Boldyreva, 1987). For engineering use, a lump-type kinetic model is commonly adopted to correlated pyrolysis data. Dumpelmann et al. (1991) developed a model for pyrolysis of sewage sludge that could predict the maximum weight loss in a fluidized bed. Conesa et al. (1997) proposed a kinetic model for the pyrolysis of anaerobically digested and nondigested sewage sludge. Conesa et al. (1998) utilized this proposed kinetic model to interpret sewage sludge pyrolysis data.

Polyelectrolyte flocculation is a common practice in wastewater treatment plant to improve the sludge dewaterability (Wu et al., 1997). The dosage of flocculant leading to the best available dewaterability is usually referred to as the "optimal dosage", whose weight fraction is generally low to the original slurry (ten to hundreds of ppm, say). In a dried filter cake, on the contrary, the residual polyelectrolyte amount could reach up to $1 \%$ by weight. All previous literature works considered pyrolysis of sludge alone. Information regarding the presence of polyelectrolyte flocculation on the pyrolysis of waste activated sludge is still largely lacking in the literature, which is the main theme of this work. 


\section{EXPERIMENTAL}

\section{Sample}

An activated sludge sample was taken on 24 February 1999 from the wastewater treatment plant of Neili Bread Plant, Presidential Enterprise Co., Taoyuan, Taiwan. The true solid density was measured by Accupyc Pycnometer 1330 (Micromeritics) with a relative deviation of less than $0.5 \%$, giving a measurement of $1457 \mathrm{~kg} / \mathrm{m}^{3}$. A particular sizer (LS230, Coulter) determined the particle size distribution as a monodispersed distribution with an average of $110.4 \mu \mathrm{m}$. The weight percentage of the dried solid, determined by drying at $102^{\circ} \mathrm{C}$, was $1.43 \%$. All tests started within $2 \mathrm{~h}$ after sampling.

Cationic polyelectrolyte T-3052, which is obtained from Kai-Guan Inc. Taiwan, was employed as the sludge flocculant. T-3052 is a cationic polyacrylamide with an average molecular weight of $10^{7}$ and charge density of $2.27 \mathrm{meq} / \mathrm{g}$. The original sludge was placed in the mixing vessel into which the polymer solution was gradually poured to make doses of 5, 15, 35, 50 and $70 \mathrm{~g}$ per $\mathrm{kg}$ dried solids (DS), respectively. The stirring was $200 \mathrm{rpm}$ for $5 \mathrm{~min}$ followed by $50 \mathrm{rpm}$ for the next $20 \mathrm{~min}$. The zetameter (ZeterMeter System 3.0, Zeter-Meter Inc., USA) measured the $\zeta$ potentials of flocculated sludge flocs. Figure 1 depicts the results. As Fig. 1 reveals, the $\zeta$ potential increased with polymer dose and reached charge neutralization point at around $15-35 \mathrm{~g}$ polymer $/ \mathrm{kg}$ DS. Figure 1 also depicts the corresponding zone settling velocity (ZSV) data of the sludge. The best settling occurs at the dose of charge neutralization point, which is referred to as the "optimal dose" of sludge. Sludge with a dosage less than $15 \mathrm{~g}$ per $\mathrm{kg}$ DS is considered underdosed, while exceeding $40 \mathrm{~g}$ per $\mathrm{kg}$ DS, overdosed.

The flocculated sludge was then vacuum-filtered to remove most of the free water. Then the dewatered samples were dried at $102^{\circ} \mathrm{C}$ for $24 \mathrm{~h}$. The dried product was crushed into fine powders of size $30 \mu \mathrm{m}$

\section{TGA test}

Chen et al. (1997) provided the experimental detail for the TGA test, which was briefly summarized herein for the sake of completeness. The thermal analyzer (SETARAM, 77A-92) was employed for recording the thermographs with argon gas (Ar) as the carrying gas. Vacuum-filtered sludge cake is the testing sample. The cell temperature was first raised from room temperature to $353 \mathrm{~K}\left(80^{\circ} \mathrm{C}\right)$ at a rate of $20^{\circ} \mathrm{C} / \mathrm{min}$, then was kept at $353 \mathrm{~K}$ for $1 \mathrm{~h}$ to remove most free water. After this stage the cell temperature was raised again to $900 \mathrm{~K}\left(627^{\circ} \mathrm{C}\right)$ at heating rates of 8 and $14^{\circ} \mathrm{C} / \mathrm{min}$, respectively. The weight-time $(w-t)$ data represent the TGA curve, whose slopes $(\mathrm{d} w / \mathrm{d} t)$ give the derivative thermogravimetric analysis (DTG) curve (Ewing, 1985).

Pore size and surface area measurement

Autopore II 9220 (Micromeretics) measures the pore volume and surface area of the dried sample prior to TGA tests. Mercury was intruded into the sample interior at different pressures, from which the incremental pore volume could be estimated. Assuming that the void portion of the sample interior consists of cylindrical pores can the pore size and the surface area data be subsequently calculated.

\section{RESULTS AND DISCUSSION}

\section{$T G A$ results}

Figure $2 \mathrm{a}-\mathrm{c}$ depicts the $\alpha$ vs $T$ data at three different heating rates. At the heating rate of $8^{\circ} \mathrm{C} /$ min, all data at various polyelectrolyte doses fall into one single curve. At 14 or $20^{\circ} \mathrm{C} / \mathrm{min}$, on the other hand, the curves of doses 15 and $35 \mathrm{~g} / \mathrm{kg}$ DS shift to the left, indicating a faster pyrolysis. Except for the doses close to charge neutralization, other tests at 14 and $20^{\circ} \mathrm{C} / \mathrm{min}$ coincide with the curves at $8^{\circ} \mathrm{C} / \mathrm{min}$. Apparently the sludge pyrolysis rates were enhanced at a high heating rate with a dose to

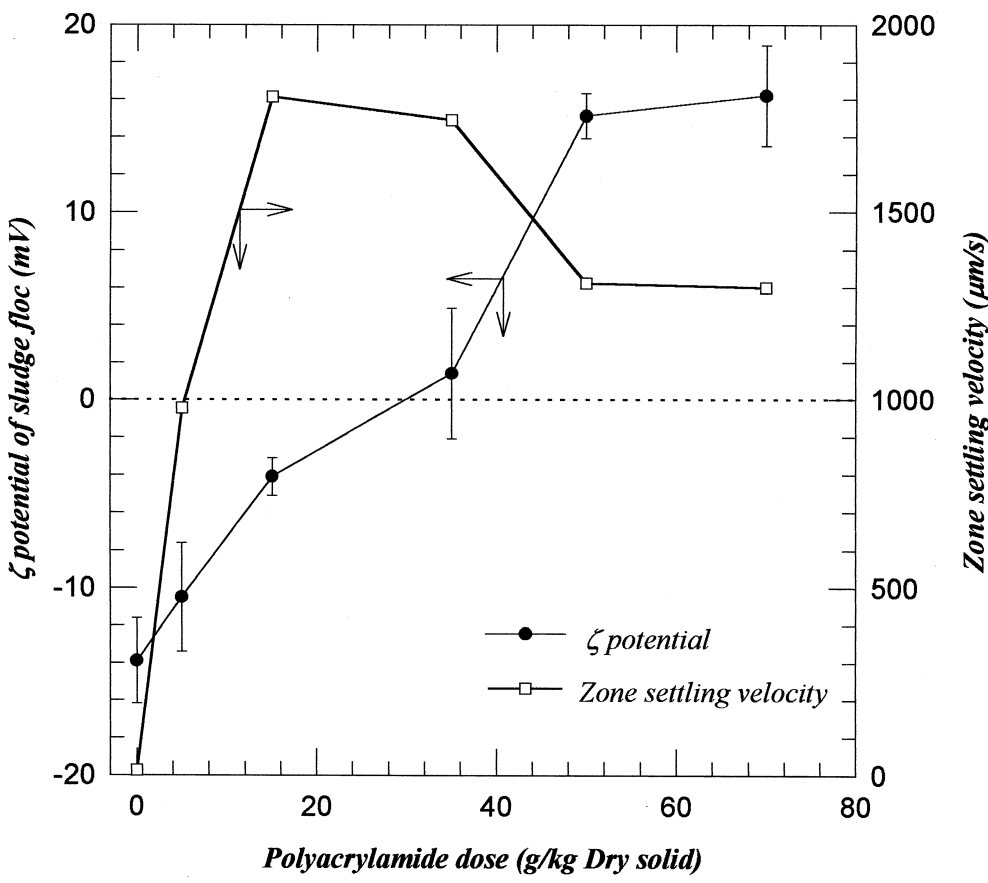

Fig. $1 . \zeta$ potential and zone settling velocity (ZSV) vs polymer dose. 
charge neutralization, which are denoted as the "speed-up" cases. Figure $3 \mathrm{a}-\mathrm{c}$ depicts the results of $\mathrm{d} \alpha / \mathrm{d} t$ vs $T$ curves. Two peaks are observed around $550 \mathrm{~K}\left(277^{\circ} \mathrm{C}\right)$ and $800 \mathrm{~K}\left(527^{\circ} \mathrm{C}\right)$, respectively, whose heights increase with heating rate. Probably two distinct reaction mechanisms exist for $T$ is lower or higher than approximately $700 \mathrm{~K}\left(427^{\circ} \mathrm{C}\right)$. As stated, two gross categories of the organics are proposed to exist in sludge. One could be decom- posed at $250-300^{\circ} \mathrm{C}$, while the other at $550-600^{\circ} \mathrm{C}$. Such an observation closely corresponds to the findings by Conesa et al. (1998). Furthermore, once the pyrolysis has been speeded up, the second peak diminished.

In sum, we demonstrated that (i) at a low heating rate of $8^{\circ} \mathrm{C} / \mathrm{min}$, the role of cationic polyacrylamide is negligible on pyrolysis rate up to $500-600^{\circ} \mathrm{C}$; (ii) at a high heating rate $\left(14\right.$ or $\left.20^{\circ} \mathrm{C} / \mathrm{min}\right)$, on the
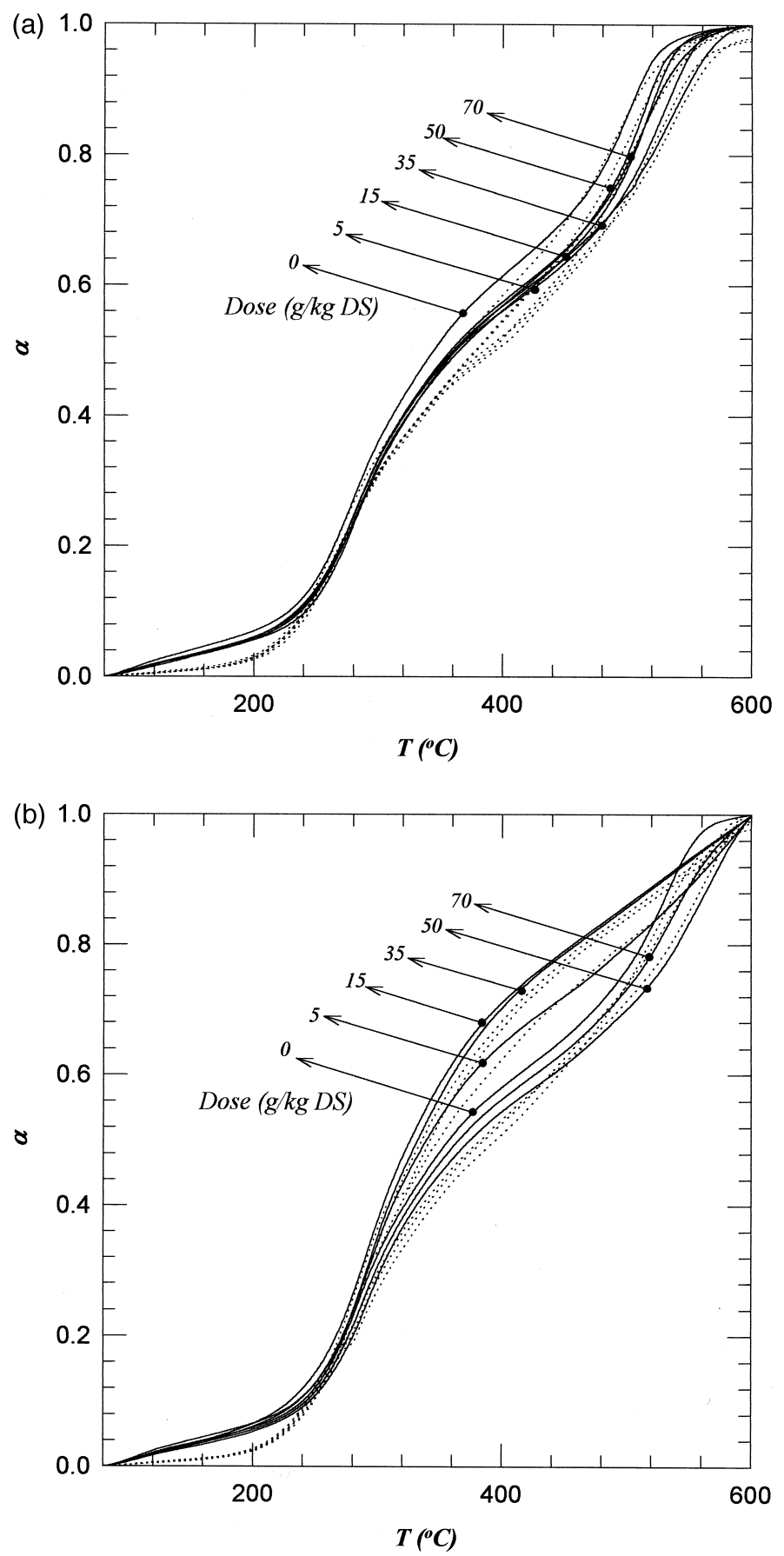

Fig. 2. The $\alpha$ vs $T$ curves. (a) $8^{\circ} \mathrm{C} / \mathrm{min}$; (b) $14^{\circ} \mathrm{C} / \mathrm{min}$; (c) $20^{\circ} \mathrm{C} / \mathrm{min}$. The dashed curves are model results based on parameters listed in Table 1. 


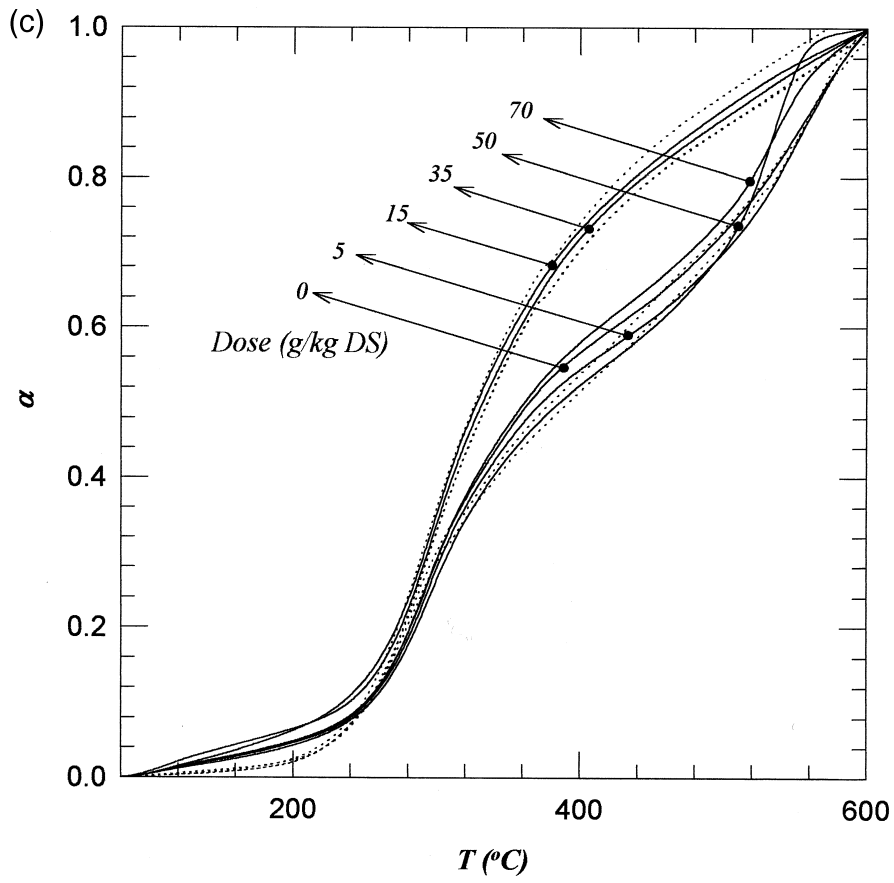

Fig. 2 (continued)

other hand, adding polyacrylamide to charge neutralization point would markedly enhance the pyrolysis rate. Point (ii) is somewhat surprising since the so-called "optimal dose" is generally considered meaningful in an aquatic environment at room temperatures, but on the pyrolysis characteristics at high temperatures. We explored this point further in the next section.

\section{Possible roles of polyacrylamide flocculation}

Figure 4 depicts the pore size data. In comparison with the results of original sludge reveals that the pore size between 10 and $100 \mu \mathrm{m}$ increases significantly with the presence of polyacrylamide. For samples of doses 0,35 and $70 \mathrm{~g} / \mathrm{kg} \mathrm{DS}$, the intrusion volumes of mercury were $0.51,0.61$ and $0.66 \mathrm{ml} / \mathrm{g}$. Consequently, the total pore areas are estimated as $22.1,28.3$ and $36.1 \mathrm{~m}^{2} / \mathrm{g}$, respectively. As stated, after flocculation, the dried and crushed sludge powders would exhibit a greater pore size and surface area. Such an observation may correlate with the enhancement in thermal decomposition rate since the available area for surface reaction increases at $35 \mathrm{~g} / \mathrm{kg}$ DS. However, we noted the slow-down of pyrolysis rate at doses exceeding $50 \mathrm{~g} /$ kg DS.

Figure 5 depicts the pyrolysis data of pure polyacrylamide. The data of original sludge is also shown in the figure for the sake of comparison. Notably, the decomposition rate of polyacrylamide is lower than that of original sludge. Polyacrylamide molecules would stick on sludge surface after flocculation. According to the patch model (Wang and Audebert, 1987), surface coverage would reach a value less than $100 \%$ at charge neutralization. In overdosing regime, the coverage could approach $100 \%$. As a result, the slow decomposition rate of the polyacrylamide may hinder the decomposition of organic materials from the (covered) sludge particle surface in the overdosing regime. Such an effect may correspond to the slow-down phenomena of thermal decomposition of sludge at dose exceeding $35 \mathrm{~g} / \mathrm{kg}$ DS.

Therefore, polyacrylamide may have two contradictory effects to pyrolysis at 14 or $20^{\circ} \mathrm{C} / \mathrm{min}$. With the action of flocculation more surface area would be available in the sludge sample that enhances pyrolysis. On the other hand, at a specific temperature polyacrylamide would decompose slower than the sludge sample, thereby hindering the thermal pyrolysis rate. The compensation of these two factors may cancel with each other that interprets the trends noted in Fig. $2 \mathrm{~b}$ and $\mathrm{c}$.

However, the above mentioned mechanisms cannot properly interpret the experimental results at $8^{\circ} \mathrm{C} / \mathrm{min}$, that is, polyacrylamide has no effects on thermal pyrolysis at $8^{\circ} \mathrm{C} / \mathrm{min}$ (Fig. 2a). It is speculated herein that at a low heating rate, the molten liquid generated from the solid surface might retain for a while before evaporation. Surface migration may thereby deteriorate the pore structure. Such a structure change may not occur at a high heating rate. There is, nevertheless, no experimental proof for such a hypothesis. 
Kinetic model

Pyrolysis reaction of sludge is significant during $200-600^{\circ} \mathrm{C}$. The detailed reaction scheme should be rather complex. Two peaks are noticeable in Fig. 3a-c, except for the cases at the charge-neutralized case at heating rates of 14 and $20^{\circ} \mathrm{C} / \mathrm{min}$. A simple kinetic model considering two parallel reactions is adopted here for engineering use. The scheme could be stated as follows:

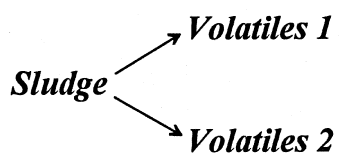

The remaining fraction of activated sludge after pyrolysis represents the inert residual.

TGA data were represented by the dimensionless conversion $\alpha$ defined as follows:
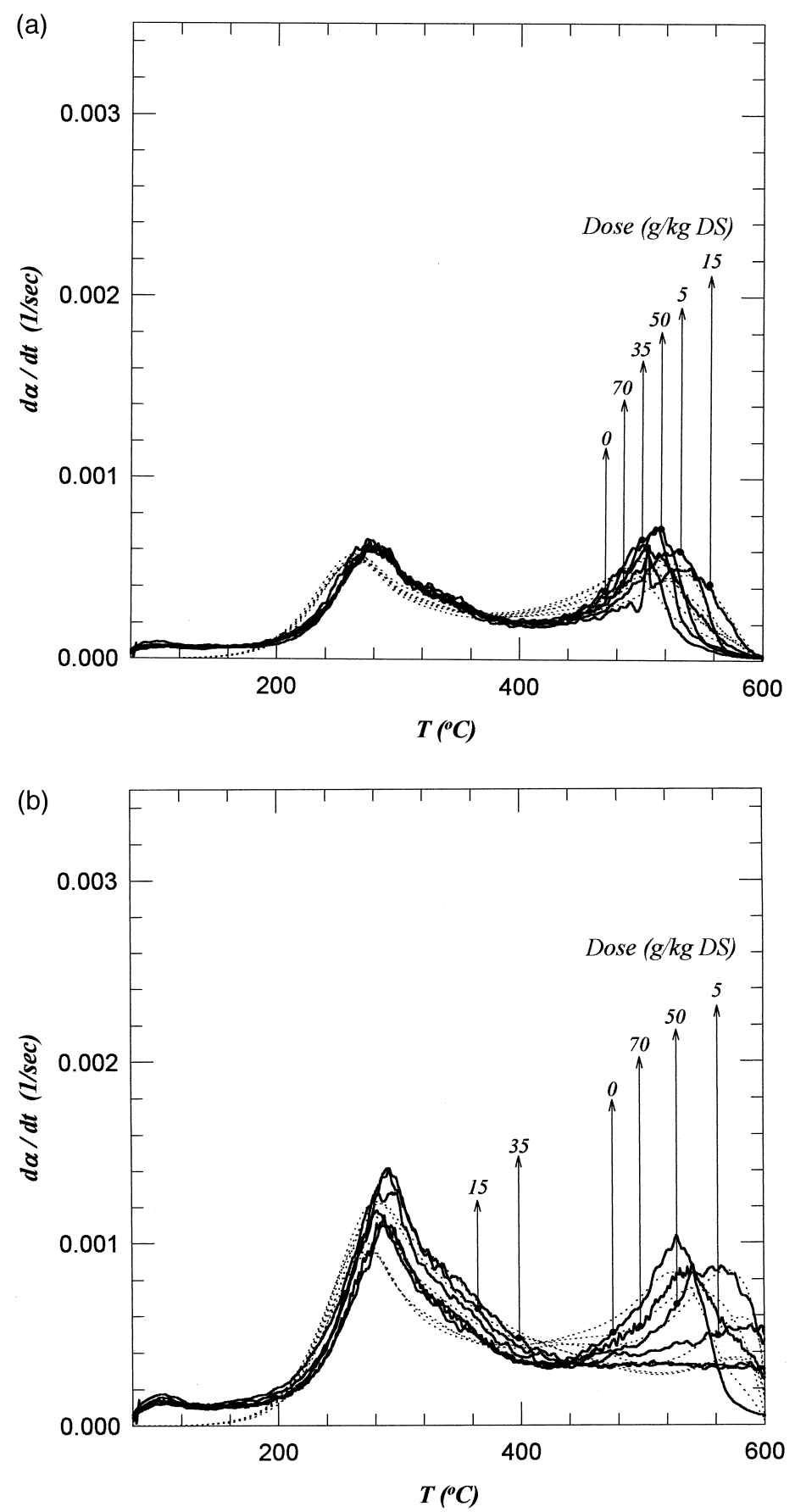

Fig. 3. The $\mathrm{d} \alpha / \mathrm{d} t$ vs $T$ curves. (a) $8^{\circ} \mathrm{C} / \mathrm{min}$; (b) $14^{\circ} \mathrm{C} / \mathrm{min}$; (c) $20^{\circ} \mathrm{C} / \mathrm{min}$. The dashed curves are model results based on parameters listed in Table 1 . 


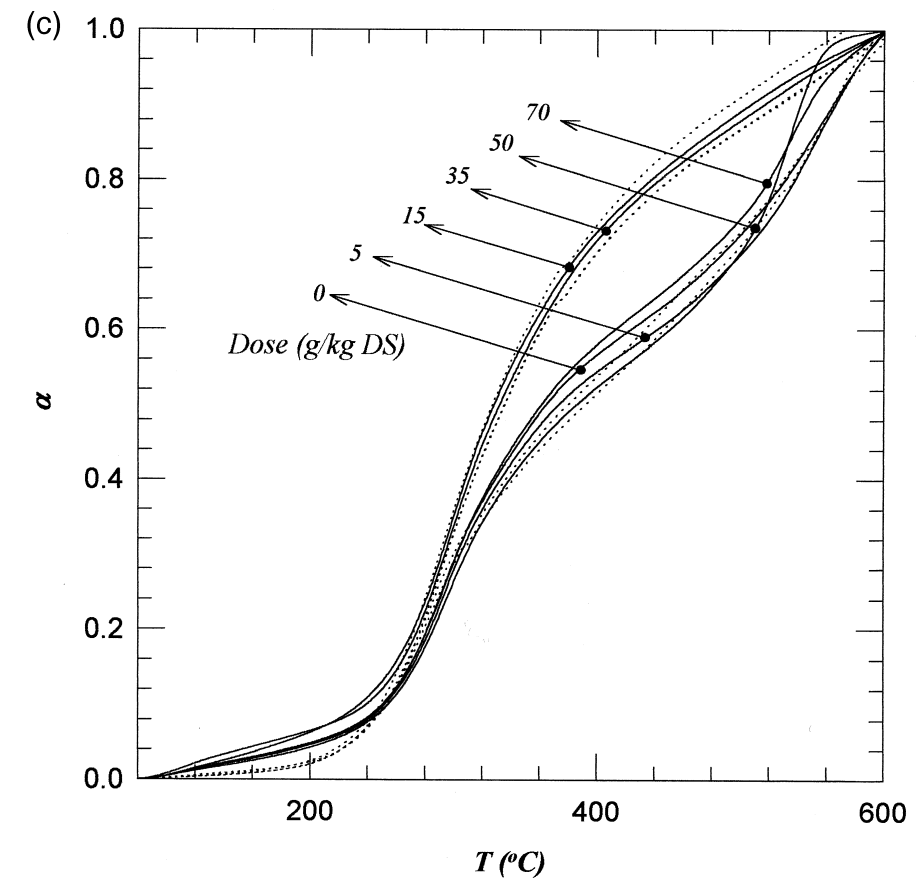

Fig. 3 (continued)

$$
\alpha=\frac{w_{i}-w}{w_{i}-w_{f}}, \quad \text { (1) } \quad \frac{\mathrm{d} \alpha}{\mathrm{d} t}=A_{1} \exp \left(\frac{-E_{1}}{R T}\right)(1-\alpha)^{n_{1}}+A_{2}
$$

where $w, w_{i}$ and $w_{f}$, are the sample weights at time $t$, at $80^{\circ} \mathrm{C}$, and at the end of test $\left(600^{\circ} \mathrm{C}\right)$, respectively. Assuming that the pyrolysis kinetic follows an Arrhenius-type expression:

$$
\exp \left(\frac{-E_{2}}{R T}\right)(1-\alpha)^{n_{2}}
$$

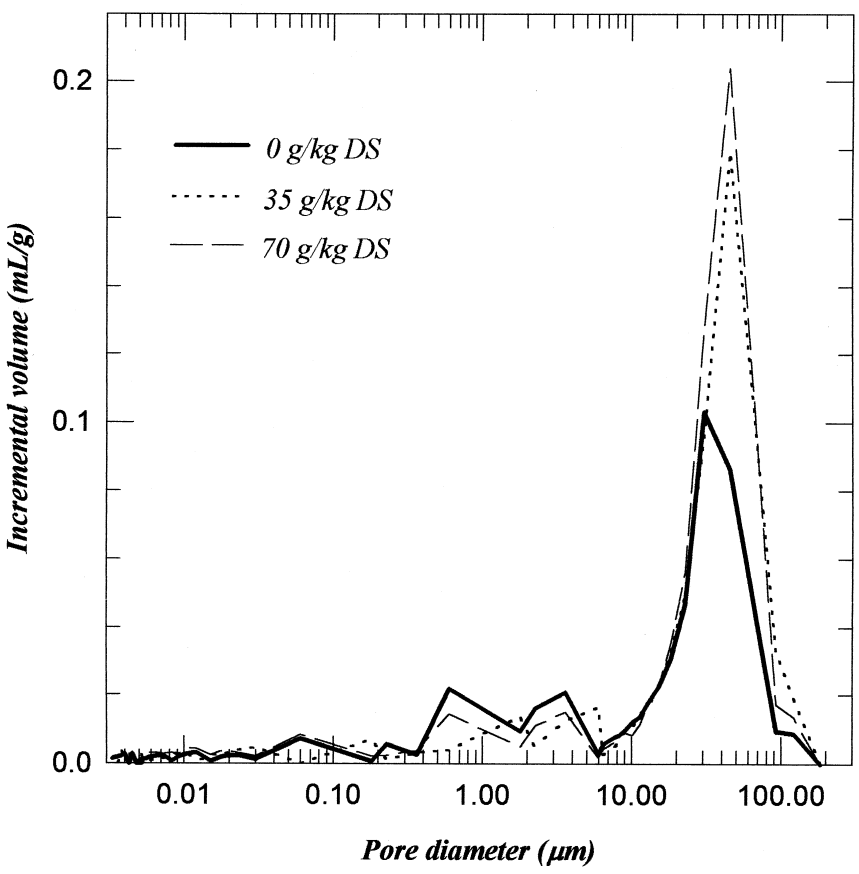

Fig. 4. The pore size distributions of sludge. 


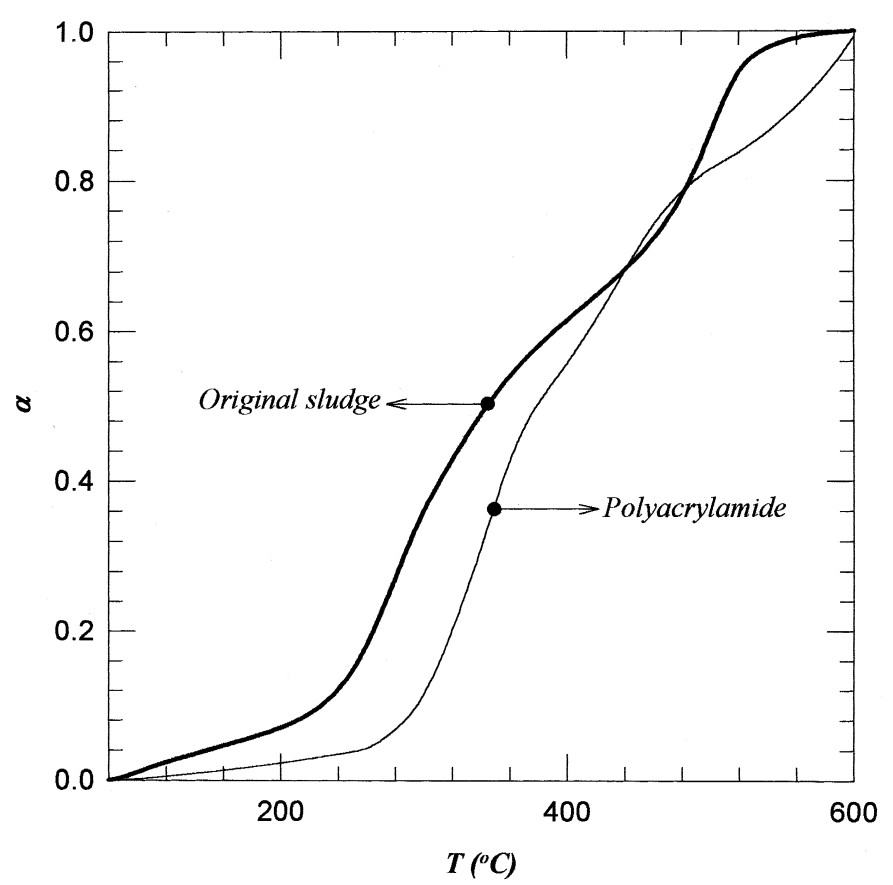

Fig. 5. Pyrolysis data of pure polyacrylamide and of original sludge.

where $E_{i}$ is the activation energy, $A_{i}$, the pre-exponential factor, $n_{i}$, the reaction order, and $R$, the gas constant.

We herein estimated the kinetic parameters $\left(A_{i}\right.$, $\left.E_{i}, n_{i}\right)(i=1,2)$ using nonlinear regression at TGA data. Table 1 lists the fitting results. The threshold temperature that divides the whole regime into reaction 1 and 2 is set at $700 \mathrm{~K}\left(427^{\circ} \mathrm{C}\right)$.

All schemes of parametric evaluation reveal that the changes in $E, A$ and $n$ are not independent. As stated, these kinetic parameters tend to compensate each other and leading to so-called "compensation effects" (Boldyreva, 1987). Although the kinetic model with different sets of fitting parameters can better describe the apparent pyrolysis behavior, they should be considered as empirical in nature. No information regarding the intrinsic chemical kinetics can be extracted therein.

Despite the "speed-up" cases, all fitting parameters exhibit similar values. For example, $E_{1}$

Table 1. Fitted kinetic parameters for the two parallel-reaction scheme in eq. (2)

\begin{tabular}{|c|c|c|c|c|c|c|}
\hline Dose (g/kg DS) & $A_{1}\left(\mathrm{~s}^{-1}\right)$ & $E_{1}(\mathrm{~J} / \mathrm{mole})$ & $n_{1}$ & $A_{2}\left(\mathrm{~s}^{-1}\right)$ & $E_{2}(\mathrm{~J} / \mathrm{mole})$ & $n_{2}$ \\
\hline \multicolumn{7}{|c|}{ (a) Temperature ramp $=8^{\circ} \mathrm{C} / \mathrm{min}$} \\
\hline 0 & 454,000 & 84,800 & 6.72 & 385,000 & 119,000 & 1.00 \\
\hline 5 & 472,000 & 85,200 & 7.66 & 389,000 & 125,000 & 0.80 \\
\hline $15^{*}$ & 423,000 & 84,900 & 7.39 & 324,000 & 126,000 & 0.84 \\
\hline $35^{*}$ & 712,000 & 87,700 & 7.52 & 407,000 & 121,000 & 0.97 \\
\hline 50 & 608,000 & 86,600 & 7.73 & 436,000 & 123,000 & 0.89 \\
\hline 70 & 588,000 & 86,500 & 7.35 & 507,000 & 124,000 & 0.96 \\
\hline \multicolumn{7}{|c|}{ (b) Temperature $\mathrm{ramp}=14^{\circ} \mathrm{C} / \mathrm{min}$} \\
\hline 0 & 924,000 & 86,700 & 7.03 & 611,000 & 125,000 & 0.83 \\
\hline 5 & 963,000 & 87,600 & 5.57 & 21,600 & 116,000 & 0.36 \\
\hline $15^{*}$ & 787,000 & 86,800 & 4.63 & 905 & 94,700 & 0.39 \\
\hline $35^{*}$ & 939,000 & 88,400 & 4.62 & 804 & 94,200 & 0.37 \\
\hline 50 & 724,000 & 86,500 & 7.48 & 24,900 & 113,000 & 0.49 \\
\hline 70 & 775,000 & 86,500 & 7.16 & 458,000 & 126,000 & 0.84 \\
\hline \multicolumn{7}{|c|}{ (c) Temperature ramp $=20^{\circ} \mathrm{C} / \mathrm{min}$} \\
\hline 0 & $1,130,000$ & 87,500 & 6.86 & 216,000 & 123,000 & 0.62 \\
\hline 5 & 901,000 & 86,500 & 7.30 & 655,000 & 129,000 & 0.67 \\
\hline $15^{*}$ & 805,000 & 86,300 & 4.10 & 753 & 87,700 & 0.57 \\
\hline $35^{*}$ & $1,200,000$ & 88,700 & 4.24 & 542 & 88,300 & 0.44 \\
\hline 50 & $1,100,000$ & 87,400 & 7.95 & $1,146,000$ & 127,000 & 0.77 \\
\hline 70 & $1,120,000$ & 87,500 & 6.62 & 664,000 & 125,000 & 0.90 \\
\hline
\end{tabular}

*Optimal dose. 
ranges from 85,000 to $91,000 \mathrm{~J} /$ mole; $n_{1}, 6.7-7.5$; $E_{2}$, around $120,000 \mathrm{~J} /$ mole; $n_{2}, 0.62-0.96$. Conesa et al. (1998) proposed that the products in off-gas stream around $250^{\circ} \mathrm{C}$ (reaction 1) include methane, carbon dioxide, water, chloromethane and acetic acid; while around $550^{\circ} \mathrm{C}$ (reaction 2), hydrogen, methane, carbon dioxide, hydrocarbons, alcohols and chloromethane. The present results reveal that the temperature dependence for reaction 1 is weaker than that is for reaction $2\left(E_{1}<E_{2}\right)$, while the trend in reactant amount dependence reverses $\left(n_{1} \gg\right.$ $n_{2}$ ).

For the speed-up cases, on the other hand, the kinetic parameters for reaction 1 are similar to those of the normal cases except for a higher $A_{1}$ and a lower $n_{1}$. Reaction 1 thereby has been enhanced at the speed-up conditions. However, since reaction 2 has been diminished when the speed-up occurs, the kinetic parameters markedly change. For instance, the pre-exponential factor $A$ becomes very low, indicating a low reaction rate. Meanwhile, $n_{2}$ reduces to around $0.4-0.5$, including a weak dependence of the pyrolyzed material. Restated, polyelectrolyte flocculation to charge neutralization point enhances reaction 1 by transforming the organics that is originally released at elevated temperature (reaction 2) to the low-temperature regime (reaction 1).

\section{Implications to application}

Although we cannot conclude the underlying mechanisms that correspond to the observed pyrolysis behavior, nonetheless, the polyelectrolyte flocculation cannot only enhance sludge dewaterability in solution, but also promote the pyrolysis rate in dried solid if the heating rate is high enough. In addition, ovedosing would deteriorate both the sludge dewaterability and the pyrolysis efficiency. Such an observation has implication to sludge management practice.

Notably, since both the heat and mass transfer resistances are negligible in a TGA test, the high heating rate corresponds to a far-from-equilibrium environment close to the sample surface. As stated, since the heating rate is rather high, sample would not reach chemical equilibrium with its environment while its (slow) surface reaction controls the pyrolysis process. If all the interpretations to the role of polyacrylamide mentioned above are correct, then to mimic a high heating rate environment, sludge pyrolysis may consider high sludge feed rate with recycling. The size of fed material should be small while the retention time should be kept short. One possible alignment is to convey thin sludge filter cake into a high-temperature furnace with a high feeding speed. Part of the product could be recycled back to the feeding point for raising the conversion. In addition, the sludge should be conditioned to charge neutralization prior to dewatering and pyrolysis.

\section{REFERENCES}

Boldyreva E. V. (1987) Problems of the reliability of kinetic data evaluated by thermal analysis. Thermochimica Acta 110, 107.

Caballero J. A., Font R., Marcillam A. and Conesa J. A. (1995) New kinetic model for the thermal decomposition of heterogeneous materials. Ind. Eng. Chem. Res. 34, 806.

Campbell H. W. and Bridle T. R. (1989) Conversion of sludge to oil: a novel approach to sludge management. Wat. Sci. Tech. 21, 1467.

Chen G. W., Chang I. L., Hung W. T., Lee S. F. and Lee D. J. (1997) Continuous classification of moisture content in waste activated sludge. J. Envir. Eng. ASCE 123, 253.

Conesa J. A., Marcilla A., Prats D. and Rodriguez-Pastor M. (1997) Waste Manag. Res. 15, 293.

Conesa J. A., Marcilla A., Moral R., Moreno-Caselles J. and Perez-Espinosa A. (1998) Evolution of gases in the primary pyrolysis of different sewage sludges. Thermochimica Acta 313, 63.

Dumpelmann R., Richarz W. and Stammbach M. R. (1991) Kinetic studies of the pyrolysis of sewage sludge by TGA and comparison with fluidized beds. Can. J. Chem. Eng. 69, 953.

Ewing G. W. (1985) Instrumental Methods of Chemical Analysis, 5th ed. McGraw-Hill, New York, pp. 429-432.

Kaminsky W., Semel J. and Sinn H. (1982) Orientierende Versuche zur Pyrolyse von Klarschlamm in einer Indirekt Beheizeten Wirbelschicht (Rapid communication). Makromol. Chem. 3, 371-375.

Kaminsky W., Augustin T., Bellmann U. and Kruger-Betz M. (1987) Recycling von Klarschlamm, eds K. J. ThomeKozmiensky and U. Loll, pp. 309-318. EF Verlag, Berlin, Germany.

Kaminsky W. and Kummer A. B. (1989) Fluidized bed pyrolysis of digested sewage sludge. J. Anal. Appl. Pyrolysis 16, 27-35.

Kislter R. C., Widmer F. and Brunner P. H. (1987) Behavior of chromium, nickel, copper, zinc, cadmium, mercury, and lead during the pyrolysis of sewage sludge. Environ. Sci. Technol. 21, 704.

Piskorz J., Scott D. S. and Westerberg I. B. (1986) Flash pyrolysis of sewage sludge. Ind. Eng. Chem. Proc. Dev. 25, 265-270.

Stammbach M. R., Kraaz B., Haggenbucher R. and Richarz W. (1989) Pyrolysis of sewage sludge in a fluidized bed. Energy Fuels 3, 225-259.

Suzuki A., Nakamura T., Yokoyama S. Y., Ogi T. and Koguchi K. (1988) Conversion of sewage sludge in heavy oil by direct thermochemical liquefaction. $J$. Chem. Eng. Japan 21, 288.

Urban D. L. and Antal M. J. (1982) Study of the kinetics of sewage sludge pyrolysis using DSC and TGA. Fuel 61, 799-806.

Wu C., Huang C. and Lee D. J. (1997) Effects of polymer dose on alum sludge dewaterability characteristics and physical properties. Colloids Surf. A. 122, 89-96. 